\title{
Patient perspectives on improving osteoarthritis management in urban and rural communities
}

This article was published in the following Dove Press journal: Journal of Pain Research

\author{
Shabana Amanda Ali' \\ Kathleen Ellen Walsh ${ }^{2}$ \\ Marita Kloseck' \\ 'Faculty of Health Sciences, University \\ of Western Ontario, London, ON, \\ ${ }^{2}$ Faculty of Science, University of \\ Western Ontario, London, ON, \\ Canada
}

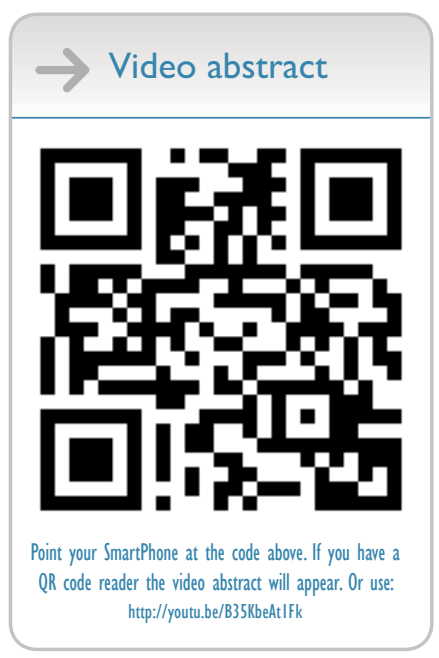

Correspondence: Shabana Amanda Ali University of Western Ontario, Arthur \& Sonia Labatt Health Sciences Building, Room 316,

II5I Richmond Street, London,

ON N6A 5B9, Canada

Tel + I 5196612111 ext 81230

Email sa.ali@mail.utoronto.ca

\begin{abstract}
Introduction: Although there is no cure for osteoarthritis (OA), there are lifestyle modifications that can mitigate symptoms such as pain, and improve management of the disease. This information is not always translated to community-dwelling seniors. Individuals in rural areas often face additional challenges due to geographic isolation and decreased access to community services. Methods: We used qualitative research methodology (hermeneutic phenomenology) to better understand the lived experiences of urban and rural community-dwelling seniors diagnosed with OA. We explored their sources of information about OA, how they manage their OA pain, and how OA management could be improved in the community. Purposeful sampling was used to recruit 20 information-rich participants (11 urban, 9 rural) in Ontario, Canada. All participants were aged $>65$ and diagnosed with OA. Semi-structured interviews were conducted, audio recorded, and transcribed verbatim. NVivo 11 Pro qualitative software was used to code transcripts.

Results: Thematic analysis revealed 9 key themes where 8 were common to urban and rural participants, and 1 was unique to rural participants. Most significant among the common themes was the description of the social network as a source of OA information, the trial-and-error approach used for OA management, and the individual contextualization of OA management. Our results suggest that there are several common experiences among urban- and rural-dwelling seniors living with OA, including the desire for support over time, but also a unique experience to rural-dwelling seniors, namely lack of access to local care.
\end{abstract}

Conclusion: These findings can be used to improve translation of OA information in both urban and rural communities in Canada, highlighting that common strategies may be effective in different contexts for this disease.

Keywords: arthritis, pain, community, phenomenology, qualitative, translation, implementation

\section{Introduction}

Osteoarthritis (OA) is a chronic and degenerative disease of the joints that is a leading cause of pain and disability among older people. ${ }^{1}$ Although there is no cure, there are strategies available to mitigate symptoms and support disease management. ${ }^{2}$ Current research is focused on identifying the causes of OA, improving treatment, and reducing the burden of the disease, ${ }^{3}$ yet there remains a breakdown in the translation and implementation of OA information from care providers to community-dwelling seniors. ${ }^{4}$ Efforts to improve this can be strengthened by including the patient perspective. ${ }^{5}$

For OA, care is primarily provided by general practitioners and clinical practice guidelines recommend education and lifestyle modifications (e.g., weight loss and exercise) to reduce symptoms. ${ }^{2,6}$ While general practitioners are aware of the benefits of lifestyle modification, this information is not always conveyed to patients. ${ }^{6-8}$ There are several limitations related to the uptake of health information by both general 
practitioners and patients. ${ }^{9}$ It is unclear whether general practitioners have the time or specific expertise to provide education and advocate for lifestyle modification. ${ }^{10,11}$ When patient education is offered, there may be a lack of understanding about how to apply the information. ${ }^{12,13}$ When left to the patient, self-management of OA has shown only minimal beneficial effect. ${ }^{14}$

Common misconceptions, including OA being a "normal part of aging" or the result of "wear-and-tear," discourage patients from seeking the care that can mitigate progression of the disease. ${ }^{15-17}$ Beyond this, where patients would go to seek this care is debatable, as there is no designated specialist for OA patients in the health care system. ${ }^{16,18}$ From the general practitioner, patients may be directed to a physiotherapist, an occupational therapist, a rheumatologist, some other specialist, or ultimately an orthopedic surgeon, at the point joint replacement surgery is indicated and opportunities for prevention are minimal. ${ }^{19}$

The health care resources that are available to communitydwelling seniors may differ in urban versus rural communities. Populations in rural areas tend to be older with less education and lower incomes than those in urban areas. ${ }^{20}$ Rural communities show higher rates of physical inactivity and obesity, factors that are known to impact OA outcomes. ${ }^{21,22}$ Rural residents are less likely to report unmet health needs, have less contact with physicians and specialists, and use emergency services more frequently than urban residents. ${ }^{23,24} \mathrm{We}$ examine the contextual factors impacting OA management in urban versus rural settings elsewhere (manuscript in preparation). To our knowledge, no previous studies have explored the individual experiences of community-dwelling seniors in managing $\mathrm{OA}$ in urban versus rural settings in Canada. ${ }^{25}$ The purpose of this study is to better understand these lived experiences and identify ways to improve the care that is available to community-dwelling seniors with $\mathrm{OA}$ in urban and rural communities.

\section{Methods}

Hermeneutic phenomenology ${ }^{26}$ was used to better understand the lived experiences of community-dwelling seniors with OA. This method was chosen in order to go beyond mere description of the phenomenon and enable interpretation of the meaning that individuals assign to the lived experience. ${ }^{27}$ Phenomenology is used to describe the essential features of an experience from the first-person perspective. Hermeneutic understanding is achieved through a dialectical process whereby description becomes interpreted in the social, cultural, and historical context of the individual, and meaning is constructed..$^{27,28}$ This interpretive process distinguishes hermeneutic phenomenology from other methodologies, where moving between parts of the experience and the whole experience, and back and forth again, increases the depth of engagement and the understanding of the lived experience. ${ }^{29}$

Purposeful sampling ${ }^{30}$ was used to recruit 20 participants who were fluent in English, aged $>65$ years, and previously diagnosed with OA. These participants were considered information-rich for the research topic under investigation, and were therefore purposely (non-randomly) recruited. ${ }^{30}$ Urban participants were recruited from a city in Ontario that had a population of 383,822 in 2016. Rural participants were recruited from a community in Ontario that had a population of 13,715 in 2016 and travel time $>30$ minutes away from urban centers. The Ontario provincial definition indicates that a rural community has a population of $<30,000$ people and is $>30$ minutes away in travel time from a community with $>30,000$ people. ${ }^{31}$ Participants were excluded if they had been previously diagnosed with another type of arthritis (e.g., rheumatoid arthritis), making our study specific to OA. Posters and flyers were distributed to local businesses, health and community centers, and additional participants were identified through snowball sampling, where existing study participants recruited potential participants from their social network. ${ }^{32}$ Interested individuals contacted the research staff by telephone or email. After providing a letter of information and discussing the study, informed consent was obtained in writing from each participant. This study was approved by The University of Western Ontario Research Ethics Board (REB approval 107183 for urban participants and 107308 for rural participants).

A convenient time and place for in-person, one-on-one, semi-structured interviews was arranged. Most meetings occurred in the participants' home or at a local community center. Interviews were conducted over a period of 7 months. An interview guide with 3 open-ended questions was used to guide the discussion; the questions were as follows: 1 ) Where do you get information related to OA? 2) How do you manage your OA pain? and 3) What can be done to improve OA management for seniors? Additional probes were used to maintain and enrich conversation over time. Interviews lasted an average of 45 minutes. Interviews were conducted in English, digitally audio recorded, and transcribed verbatim. Each participant also completed an OA screening test and demographic questionnaire. The OA screening test was composed of 10 questions where affirmative answers indicated the presence of OA (Figure S1). All data were de-identified to ensure confidentiality. 
To understand the participant's experience as a whole, 2 authors (SAA and KEW) independently listened to the interview audio and read the interview transcripts several times. Next, SAA and KEW each independently performed inductive thematic analysis for all transcripts through lineby-line, selective, and wholistic analyses. ${ }^{26,27}$ Groups of words and phrases that reflected the same concept were labeled using codes. After multiple rounds of coding both urban and rural transcripts, SAA and KEW had each generated codes [1] within and across urban transcripts, [2] within and across rural transcripts, and [3] across urban and rural transcripts. NVivo 11 Pro Software ${ }^{\odot}$ (QSR International, Doncaster, VIC, Australia) was used to combine and refine the final coding list. Through discussion among all authors, codes were grouped into subthemes with shared meanings, and interpreted within the social, cultural, and historical context of the individual's experiences with OA. From these, themes emerged and similarities and differences were examined between urban and rural findings.

To ensure reliability, an independent researcher (KMK) analyzed a subset of urban and rural transcripts and participated in discussions about the emerging themes. To ensure accuracy, themes were considered against the original transcripts to verify that all codes were captured and appropriately reflected by the themes. Thematic saturation ${ }^{27}$ was agreed upon after this iterative process was used to analyze results from 11 urban and
9 rural participants. ${ }^{33}$ No new results emerged and a shared understanding of the phenomenon was held by all coauthors, so no additional participants were interviewed.

\section{Results}

A total of 20 participants were included in this study. Participant demographics are presented in Table 1 . The majority of urban and rural participants were of similar age (72 years), sex (female), education (greater than high school completed), and occupational status (retired). Most participants lived with a spouse or partner. Urban participants tended to rate their overall health and OA as worse than did rural participants, based on self-reported assessments. Similar proportions of urban and rural participants began experiencing OA symptoms prior to age 45 years, between ages 45 and 55 years, and between ages 56 and 65 years. Most participants experienced joint pain daily. From inductive thematic analysis of interview transcripts, 9 key themes emerged and of these, 8 were common to urban and rural participants, and 1 was unique to rural participants. A summary of key themes and illustrative quotes is presented in Table 2.

\section{Urban and rural experiences}

\section{Community services}

Participants in both urban and rural settings primarily referred to The Arthritis Society, Canada's largest non-profit

Table I Participant demographics

\begin{tabular}{|c|c|c|}
\hline Characteristic & Urban participants (N=I I) & Rural participants $(\mathbf{N}=9)$ \\
\hline Average age (years) & 72 (range 67-83) & 72 (range 68-8I) \\
\hline Sex & Female $82 \%(n=9)$ & Female $78 \%(n=7)$ \\
\hline \multirow[t]{2}{*}{ Education level } & High school completed 55\% (n=6) & High school completed II\% (n=I) \\
\hline & College/university completed $45 \%(n=5)$ & College/university completed $89 \%(n=8)$ \\
\hline \multirow[t]{2}{*}{ Occupational status } & Employed part-time $9 \%(n=I)$ & Employed full-time $22 \%(n=2)$ \\
\hline & Retired $91 \%(n=10)$ & Retired $78 \%(n=7)$ \\
\hline \multirow[t]{3}{*}{ Current living arrangements } & Alone $9 \%(n=1)$ & Alone $22 \%(n=2)$ \\
\hline & With spouse/partner $82 \%(n=9)$ & With spouse/partner $67 \%(n=6)$ \\
\hline & With other family member $9 \%(n=I)$ & With other family member II\% $(n=I)$ \\
\hline \multirow[t]{4}{*}{ Self-rated assessment of overall health } & Excellent $27 \%(n=3)$ & \\
\hline & Good 27\% (n=3) & Good $56 \%(n=5)$ \\
\hline & Fair $36 \%(n=4)$ & Fair $44 \%(n=4)$ \\
\hline & Poor $9 \%(n=1)$ & \\
\hline \multirow[t]{5}{*}{ Self-rated assessment of osteoarthritis } & Good 9\% (n=I) & Good 22\% (n=2) \\
\hline & Fair $18 \%(n=2)$ & Fair $56 \%(n=5)$ \\
\hline & Poor $45 \%(n=5)$ & Poor 22\% $(n=2)$ \\
\hline & Extremely bad $18 \%(n=2)$ & \\
\hline & No response $9 \%(n=1)$ & \\
\hline Age (years) of onset of osteoarthritis & Before age $4536 \%(n=4)$ & Before age $4534 \%(n=3)$ \\
\hline \multirow[t]{2}{*}{ symptoms } & Age $45-5527 \%(n=3)$ & Age $45-5522 \%(n=2)$ \\
\hline & Age $56-6536 \%(n=4)$ & Age $56-6544 \%(n=4)$ \\
\hline \multirow[t]{3}{*}{ Frequency of joint pain experienced } & Weekly $9 \%(n=I)$ & Weekly 22\% (n=2) \\
\hline & Daily 55\% $(n=6)$ & Daily $56 \%(n=5)$ \\
\hline & Always $36 \%(n=4)$ & Always $22 \%(n=2)$ \\
\hline
\end{tabular}


Table 2 Themes resulting from inductive thematic analysis, with examples from urban $(U)$ and rural $(R)$ participants

\begin{tabular}{|c|c|}
\hline Themes & Verbatim example [participant ID] \\
\hline \multicolumn{2}{|c|}{ Common themes among urban and rural participants } \\
\hline \multirow[t]{5}{*}{ Community services } & I've never had anything to do with The Arthritis Society. I read about it and listened to their speeches, but \\
\hline & I don't think it's for me [...]. It doesn't seem to have the symptoms I have. Arthritis, it comes and goes and \\
\hline & does different things. Osteoarthritis is different because your bones wear away. [U7] \\
\hline & I think for sure they (The Arthritis Society) are lacking, if I don't even know they are in the area, unless I've \\
\hline & drawn a complete blank. I think that is super lacking. $[R I]$ \\
\hline \multirow[t]{4}{*}{ Social networks } & Everybody always feels better after they talked to somebody, we always feel kind of supported. I'm not the \\
\hline & only one who's got this pain! [U9] \\
\hline & My sister was the first one who told me a better get to a doctor because I was limping but I said it doesn't \\
\hline & hurt. But you're limping! You better get to a doctor. [R8] \\
\hline \multirow[t]{3}{*}{ Self-directed information seeking } & I look at every bulletin board, I read every newspaper, I read every event that's happening [...] but a lot of \\
\hline & people aren't into that. [U8] \\
\hline & I do my own investigation [...] it is best to get your own information. [R4] \\
\hline \multirow[t]{4}{*}{ Attitudes toward medication } & I have medication that I have, but I'm not taking it if I don't have to [...] I have a phobia with medications. If \\
\hline & I don't have to take it, I don't. [U5] \\
\hline & One thing I keep asking her (general practitioner) is what damage am I doing to myself with the medications \\
\hline & I'm on and I never really get that explained to me. [R4] \\
\hline \multirow[t]{5}{*}{ Formal support } & The doctor has given me a little information. Actually, very little. Basically, her information has been, uhh, \\
\hline & you know what, live with it [...] But you see to me, that's a no-good answer. Yeah, I now know, there is \\
\hline & something you could do about it. [U2] \\
\hline & I don't go in completely complaining about my hands or my fingers too. So I guess they don't really address \\
\hline & it that much. $[R I]$ \\
\hline \multirow[t]{3}{*}{ Trial and error } & l've learned to never say no and never say never [...] if somebody came along to me and said, hey you \\
\hline & know what? This is the greatest, and you know [...] why not try it? [U3] \\
\hline & I don't know if there is any evidence, but it (strategy) certainly made a difference for me. [R5] \\
\hline \multirow[t]{4}{*}{ Facilitators of OA management } & [...] workshops that were addressing strictly OA, that would be more of a positive step for people like me. \\
\hline & A general arthritis workshop, I don't think works if you have something specific. [UII] \\
\hline & If people were more aware of how bad it can be, how painful it can be, you know, just like the people who \\
\hline & don't have it $[\ldots]$ helpful for them to understand what you are going through. [R2] \\
\hline \multirow[t]{4}{*}{ Individual contextualization of OA } & If you've got it, you've got it, I don't think there's any cure for it period. I think if you've got osteoarthritis your \\
\hline & bones are wearing away, it doesn't matter what you're plastering them with, it's not going to stop it! [U7] \\
\hline & I think people who sit back and let it get to them are just going to get worse. I get up and keep working to \\
\hline & make sure l'm on the move all the time. [R4] \\
\hline \multicolumn{2}{|c|}{ Unique theme among rural participants } \\
\hline \multirow[t]{4}{*}{ Access to local care } & They don't offer any afterhours clinic $[\ldots]$ We are very neglected in that regard up here (rural setting) $[\ldots]$ \\
\hline & We are very underserviced in many ways. $[\mathrm{RI}]$ \\
\hline & So my arthritis, because I go to a doctor at (urban setting), now I just go once a year [...] my information \\
\hline & comes from when I see my doctor in (urban setting). [R7] \\
\hline
\end{tabular}

Abbreviation: OA, osteoarthritis.

organization providing education and services for arthritis,${ }^{34}$ as a source of OA information. Not all participants were aware of this organization (Table 2), and those who were appeared unclear as to the services offered by them. A majority of participants, whether or not they were aware of The Arthritis Society, did not access their services in urban ("I've never had an Arthritis Society pamphlet in my hand." [U3]) nor rural ("I've never used them [The Arthritis Society] for my arthritis." [R8]) communities. Multiple urban participants expressed disappointment over losing an arthritis education program by a local hospital that had been discontinued 10 years prior. Among rural participants, no additional arthritis-specific community resources were mentioned.

\section{Social networks}

Almost all participants described information related to OA management being obtained through a family or friend. These social networks appeared to be a prominent source of OA information for both urban and rural participants, and also a source of support (Table 2). Participants compared their individual experiences with OA relative to that of their peers. There was a clear reliance on the experiences and anecdotal information from the social network, particularly for the trial-and-error approach to new remedies.

This one particular person that I was talking to, I had a real flare up this one time $[\ldots]$ and she said she bought this (ointment) or something and extra strength, and she said it is so good. Well I went out the next day and got it. [R2] 
This reliance on the immediate social network was common across urban and rural participants.

\section{Self-directed information seeking}

The individual information-seeking behaviors of participants determined whether, and to what extent, they would engage in self-directed learning. Some participants readily accessed information through various sources and were willing to try new things, effectively taking responsibility of their prognosis (Table 2). There were clear barriers to interpreting and trusting information available in the public domain.

I always check everything out with (rheumatologist) if I have any real concerns [...] I don't sort of always just take from the Internet because you're not quite sure where it's coming from. [U9]

These challenges were found in both urban and rural settings, where some participants used the Internet and others did not, and some felt overwhelmed by the volume of information available.

\section{Attitudes toward medication}

Several participants in both urban and rural settings described a preference to abstain from medication, for some due to concerns over side effects (Table 2). A commonly reported experience was the tendency for general practitioners to prescribe medication as the default treatment option.

I think they (general practitioners) should be checking the medication more [...]. I've never been asked is it working or how do you feel on it? They just keep renewing it. All of a sudden I'm thinking, I don't think this stuff is working right. [R3]

Many participants preferred hearing about alternative strategies and suggested that general practitioners should provide this information, with 1 participant saying, "Have a little bit of maybe pamphlets in there (the doctor's office) [...] talk to us and stop pushing pills!" [U4]. Across settings, participants were being prescribed medications despite their preferences for alternative management strategies.

\section{Formal support}

Some participants described positive experiences with their general practitioners while others expressed a lack of information and support (Table 2). Many participants felt their time with general practitioners was limited or rushed, and that OA was not a priority. Some participants had more positive experiences with specialists who they believed to help with their OA. "I get more explanation from the physiotherapist than I do from my medical doctor." [R2] The accuracy and consistency of the information provided by some specialists was unclear. A rural participant explained her confusion after having joint replacement surgery and being instructed by one specialist not to move the joint for 6 weeks, while another specialist told her to start moving it immediately. Overall, participants expressed uncertainty in the ability of formal care providers to help with OA management.

\section{Trial and error}

All participants described experiences with trying a new strategy with the expectation that it would reduce their OA symptoms. Some participants tried more strategies than others, but there was a clear trial-and-error approach by both urban and rural participants that resulted in them becoming experts in their own care (Table 2).

Over the years, I have learned what to do and what not to do. In the pool was for instance, and on the machines especially, how much weight I can tolerate. [U5]

Across settings, most participants were willing to at least try a new management strategy as they became aware of them, while others felt the effort was futile given the lack of cure for OA.

\section{Facilitators of OA management}

Participants identified a variety of strategies that they believed would help community-dwelling seniors to better manage their OA. OA-specific education was a key priority over general arthritis education, with OA-specific information being provided early to prevent the propagation of myths (Table 2).

I think if more people were encouraged to go on The Arthritis

Society website, because that's where the majority of information would be available, I think that would be helpful. [R6]

Some participants wanted more attention to OA from general practitioners, with formal recognition of OA as manageable. One participant described the need for a community-based resource dedicated to OA treatment.

People should get out and talk to each other and share information [...] I think there should be a nurse or somebody available or some kind of $[. .$.$] health center where people$ can just go (for OA). [U1]

Participants in both urban and rural settings expressed the need for ongoing support, with an existing role for spouses in assisting with daily tasks, and a potential role for peer leaders in sharing experiences.

\section{Individual contextualization of $\mathrm{OA}$}

There was a distinct delineation between participants who felt hopeful about finding new ways to change their prognosis 
and participants who felt helpless to their symptoms ever improving (Table 2). Participants expressed determination ("I try to do everything as normal and just deal with the pain," [R2]), adjustments to daily life ("I try not to let it affect my life, but I mean it does. Like I say, when sometimes I'm in really bad pain and I just don't do what I normally do," [U10]), stubbornness ("When I want to do something I do it and when I do it I do pay for it usually," [R3]), frustration ("I like to cook and be in the kitchen. If I can't open a jar I want to heave it right through the window," [U6]), worry ("I worry about my hands and whether I'll be able to do things like comb my hair and feed myself," [U9]), and resignation ("I don't think there is anything out there," [R7]).

Some participants were motivated by peers ("One lady has very severe rheumatoid, and she's pretty much my inspiration, because she just keeps going," [U2]) while others preferred not to dwell on the topic ("We [social circle] don't discuss it, other than we're getting old. We put it in the whole context of this is the way it is when you get old," [U6]). There was also a disconnect between knowledge and behavior where participants in both urban and rural settings might be aware of strategies available, but did not engage in them.

\section{Rural experiences}

\section{Access to local care}

Rural participants described having difficulty obtaining appointments and maintaining a general practitioner over the long term.

I've had 4 (general practitioners) within the last 5 years.

They come and go so the last one left a year and a half ago and I don't have one [...] just doesn't seem right when you are a senior citizen and you lived here (rural community) all your life, and you don't have a doctor. [R7]

Many rural participants resorted to using the local emergency department for their health needs, including OA. There was a clear lack in accessing community services, where all rural participants were aware of The Arthritis Society, but only 1 participant had used their services. Several rural participants described the lack of access to health care services compared with urban settings (Table 2), indicating potential barriers to appropriate and timely OA care.

\section{Discussion}

This is the first qualitative study seeking to better understand the lived experiences of community-dwelling seniors in managing OA in urban and rural settings in Ontario, Canada. While previous reports highlight the differences in health care that exist between urban and rural settings, ${ }^{25,35,36}$ we found similarities in the lived experiences of community-dwelling seniors in managing OA in urban and rural settings. The strength of our approach was the comprehensive understanding achieved through in-depth examination of the interviews with each carefully selected participant.

Participants in this study obtained information related to OA from community services, social networks, and selfdirected information seeking. We identified a lack of awareness combined with a lack of understanding of what services are available for OA information and care. In Canada, The Arthritis Society is uniquely equipped to offer education and support for OA, ${ }^{34}$ but there are barriers preventing people from accessing the services. One solution is improved public campaigning to promote existing community-based services. Future research is needed to determine what ways are most effective for engaging isolated populations, including socially isolated seniors and geographically isolated rural communities with a lack of access to OA services.

We identified heavy reliance on informal social networks as a source of information and support. Consistent with previous reports on arthritis information-seeking behavior, ${ }^{37}$ individual differences impacted the propensity to seek OA information. The reliance on social networks can be leveraged to promote uptake and sustainability of OA management strategies. ${ }^{38}$ Since the quality of information exchanged within social networks is unclear and may propagate myths, structured opportunities for social networking may promote evidence-based information exchange among peers. Monthly gatherings with a peer leader trained in OA management strategies may help facilitate the trial-and-error approach used by so many. Future research is needed to determine the best structure (frequency, format, and content) for social networking to disseminate information and reinforce behavior change for OA. ${ }^{39}$

Participants described various methods of managing their OA pain, including medication, formal support, and trial and error. There was an overall dissatisfaction with existing strategies for OA management, with many participants expressing disapproval of medication, lack of support from general practitioners, and trial-and-error approaches to new management strategies. Regardless of urban versus rural setting, participants could be grouped by their outlook on OA management, where some felt hopeful and others felt helpless. These findings highlight the need for personalized OA care, where adoption of management strategies may be improved if they are tailored to meet the needs of the individual. ${ }^{40}$ Future research is needed to characterize the biopsychosocial impact 
of $\mathrm{OA},{ }^{41}$ since these factors may impact clinical outcomes. ${ }^{42}$ For example, avoidance behaviour is considered a mediator of chronic musculoskeletal pain-related disability. ${ }^{43}$ Many of the examples we provided in Table 2 relate to the effects of pain strategies to avoid pain. The avoidance of pain is a likely driver behind the management strategies used by community-dwelling seniors with OA.

Participants identified several ways in which OA management could be improved for seniors. Facilitators of OA management included greater support over time and improved community services, particularly in rural settings. Individual contextualization of OA based on positive or negative personal views appeared to significantly impact the likelihood of participants seeking improved management or becoming resigned to the disease, again highlighting the need for personalized OA care. The disconnect between general practitioners, specialists, and community services for OA care resulted in information being incomplete, conflicting, or inaccurate ${ }^{44}$ Our findings suggest that general practitioners could more consistently endorse and refer patients with OA to The Arthritis Society, ${ }^{34}$ or other community services with the expertise and resources to provide detailed OA care.

While the majority of our findings are consistent with previous studies, this is the first report identifying more similarities than differences in OA care across urban and rural settings. As such, we have identified common barriers that can be overcome to improve OA care for both urban- and rural-dwelling seniors in Canada. Though there is evidence to support tailoring health services to local contexts ${ }^{45}$ our findings suggest that there is also an opportunity to improve OA care in a general capacity across contexts. By focusing on the patient perspective in this study, we identified self-reported challenges that can be overcome to improve patient-centered OA care. ${ }^{46}$

\section{Limitations}

The participants in this study were demographically homogeneous. A larger representation of females could be expected based on the higher prevalence of OA in females. ${ }^{47}$ The results of phenomenological studies are not meant to be generalized to larger populations, ${ }^{48}$ but our findings do suggest that there are common experiences that may inform improved OA management across urban and rural contexts. Future studies with larger sample sizes and different methodological approaches are needed to establish external validity. Whether general practitioners should be the gatekeepers to all formal and informal OA care could not be determined, ${ }^{49}$ as we did not capture the perspectives of general practitioners nor specialists in the present study.

\section{Conclusion}

Through exploration of the lived experiences of communitydwelling seniors with OA in urban and rural settings, we identified several key themes that could inform future research and practice to improve translation and implementation of OA information. Our findings suggest that OA care might be improved through greater public awareness of available community services, through opportunities for seniors to exchange validated information and support, through tailored management strategies based on individual needs, and through better integration of services. Given that our findings were largely similar between urban and rural settings in Canada, common translation and implementation strategies may prove effective for improving OA outcomes across these different contexts.

\section{Acknowledgments}

The authors thank the individuals who participated in this study. We also thank Kristina M Kokorelias for independently analyzing interview transcripts and sharing her interpretation. SAA was supported by a Transdisciplinary Bone \& Joint Training Award from the Collaborative Training Program in Musculoskeletal Health Research and the Sam Katz Community Health and Aging Research Unit at The University of Western Ontario.

\section{Author contributions}

SAA and MK conceptualized the study. SAA and KEW collected and analyzed data. SAA wrote the manuscript, KEW and MK revised the manuscript. All authors contributed toward data analysis, drafting and revising the paper and agree to be accountable for all aspects of the work.

\section{Disclosure}

The authors report no conflicts of interest in this work.

\section{References}

1. Neogi T, Zhang Y. Epidemiology of osteoarthritis. Rheum Dis Clin North Am. 2013;39(1):1-19.

2. Hochberg MC, Altman RD, April KT, et al; American College of Rheumatology. American College of Rheumatology 2012 recommendations for the use of nonpharmacologic and pharmacologic therapies in osteoarthritis of the hand, hip, and knee. Arthritis Care Res (Hoboken). 2012;64(4):465-474.

3. Glyn-Jones S, Palmer AJ, Agricola R, et al. Osteoarthritis. Lancet. 2015;386(9991):376-387.

4. Ali SA, Kloseck M, Lee K, Walsh KE, MacDermid JC, Fitzsimmons D. Evaluating the design and reporting of pragmatic trials in osteoarthritis research. Rheumatology (Oxford). Epub 2017 Mar 24

5. Ibrahim SA, Siminoff LA, Burant CJ, Kwoh CK. Variation in perceptions of treatment and self-care practices in elderly with osteoarthritis: a comparison between African American and white patients. Arthritis Rheum. 2001;45(4):340-345. 
6. Nelson AE, Allen KD, Golightly YM, Goode AP, Jordan JM. A systematic review of recommendations and guidelines for the management of osteoarthritis: the chronic osteoarthritis management initiative of the U.S. bone and joint initiative. Semin Arthritis Rheum. 2014;43(6):701-712.

7. DeHaan MN, Guzman J, Bayley MT, Bell MJ. Knee osteoarthritis clinical practice guidelines - how are we doing? J Rheumatol. 2007;34(10):2099-2105.

8. Denoeud L, Mazieres B, Payen-Champenois C, Ravaud P. First line treatment of knee osteoarthritis in outpatients in France: adherence to the EULAR 2000 recommendations and factors influencing adherence. Ann Rheum Dis. 2005;64(1):70-74.

9. Robbins L, Kulesa MG. The state of the science in the prevention and management of osteoarthritis. Am J Nurs. 2012;112(3):25-33.

10. Cottrell E, Roddy E, Foster NE. The attitudes, beliefs and behaviours of GPs regarding exercise for chronic knee pain: a systematic review. BMC Fam Pract. 2010;11:4.

11. Cabana MD, Rand CS, Powe NR, et al. Why don't physicians follow clinical practice guidelines? A framework for improvement. JAMA. 1999;282(15):1458-1465.

12. Juhl C, Christensen R, Roos EM, Zhang W, Lund H. Impact of exercise type and dose on pain and disability in knee osteoarthritis: a systematic review and meta-regression analysis of randomized controlled trials. Arthritis Rheumatol. 2014;66(3):622-636.

13. Quintrec JL, Verlhac B, Cadet C, et al. Physical exercise and weight loss for hip and knee osteoarthritis in very old patients: a systematic review of the literature. Open Rheumatol J. 2014;8:89-95.

14. Kroon FP, van der Burg LR, Buchbinder R, Osborne RH, Johnston $\mathrm{RV}$, Pitt V. Self-management education programmes for osteoarthritis. Cochrane Database Syst Rev. 2014;1:CD008963.

15. Alami S, Boutron I, Desjeux D, et al. Patients' and practitioners' views of knee osteoarthritis and its management: a qualitative interview study. PLoS One. 2011;6(5):e19634.

16. Prasanna SS, Korner-Bitensky N, Ahmed S. Why do people delay accessing health care for knee osteoarthritis? Exploring beliefs of health professionals and lay people. Physiother Can. 2013;65(1):56-63.

17. Thielke S, Sale J, Reid MC. Aging: are these 4 pain myths complicating care? J Fam Pract. 2012;61(11):666-670.

18. Foster NE, Hartvigsen J, Croft PR. Taking responsibility for the early assessment and treatment of patients with musculoskeletal pain: a review and critical analysis. Arthritis Res Ther. 2012;14(1):205.

19. Mazzuca SA, Brandt KD, Katz BP, et al. Comparison of general internists, family physicians, and rheumatologists managing patients with symptoms of osteoarthritis of the knee. Arthritis Care Res. 1997;10(5):289-299.

20. Kinsley C. Rural Health in Rural Hands: Strategic Directions for Rural, Remote, Northern and Aboriginal Communities. Ministerial Advisory Council on Rural Health; 2002. Available from: http://publications. gc.ca/site/eng/9.689374/publication.html. Accessed January 12, 2018.

21. Hill JL, You W, Zoellner JM. Disparities in obesity among rural and urban residents in a health disparate region. BMC Public Health. 2014;14:1051.

22. Felson DT, Lawrence RC, Dieppe PA, et al. Osteoarthritis: new insights. Part 1: the disease and its risk factors. Ann Intern Med. 2000;133(8):635-646.

23. Haggerty JL, Roberge D, Pineault R, Larouche D, Touati N. Features of primary healthcare clinics associated with patients' utilization of emergency rooms: urban-rural differences. Healthc Policy. 2007;3(2):72-85.

24. Sibley LM, Weiner JP. An evaluation of access to health care services along the rural-urban continuum in Canada. BMC Health Serv Res. 2011;11:20.

25. Jordan JM, Linder GF, Renner JB, Fryer JG. The impact of arthritis in rural populations. Arthritis Care Res. 1995;8(4):242-250.

26. Van Manen M. Researching Lived Experience: Human Science for an Action Sensitive Pedagogy. Albany, NY, USA: State University of New York Press; 1990.

27. Crist JD, Tanner CA. Interpretation/analysis methods in hermeneutic interpretive phenomenology. Nurs Res. 2003;52(3):202-205.

28. Flood A. Understanding phenomenology. Nurse Res. 2010;17(2):7-15.
29. Laverty SM. Hermeneutic phenomenology and phenomenology: a comparison of historical and methodological considerations. Int J Qual Methods. 2003;2(3):21-35.

30. Palinkas LA, Horwitz SM, Green CA, Wisdom JP, Duan N, Hoagwood K. Purposeful sampling for qualitative data collection and Analysis in Mixed Method Implementation Research. Adm Policy Ment Health. 2015;42(5):533-544.

31. Fjeldsted H. Rural and Northern Health Care Framework/Plan. Ministry of Health and Long-Term Care; 2010. Available from: http:// www.health.gov.on.ca/en/public/programs/ruralnorthern/report.aspx. Accessed January 12, 2018.

32. Guetterman TC. Descriptions of sampling practices within five approaches to qualitative research in education and the health sciences. 2015;16(2).

33. Crouch M, McKenzie H. The logic of small samples in interview-based qualitative research. Soc Sci Inf. 2006;45(4):483-499.

34. The Arthritis Society. Available from: https://arthritis.ca/. Accessed December 3, 2016.

35. Saag KG, Doebbeling BN, Rohrer JE, Kolluri S, Mitchell TA, Wallace RB. Arthritis health service utilization among the elderly: the role of urban-rural residence and other utilization factors. Arthritis Care Res. 1998;11(3):177-185.

36. Brundisini F, Giacomini M, DeJean D, Vanstone M, Winsor S, Smith A. Chronic disease patients' experiences with accessing health care in rural and remote areas: a systematic review and qualitative meta-synthesis. Ont Health Technol Assess Ser. 2013;13(15):1-33.

37. Ellis J, Mullan J, Worsley A, Pai N. The role of health literacy and social networks in arthritis patients' health information-seeking behavior: a qualitative study. Int J Family Med. 2012;2012:397039.

38. Crotty M, Prendergast J, Battersby MW, et al. Self-management and peer support among people with arthritis on a hospital joint replacement waiting list: a randomised controlled trial. Osteoarthritis Cartilage. 2009; 17(11):1428-1433.

39. Lorig K, Gonzalez VM, Laurent DD, Morgan L, Laris BA. Arthritis self-management program variations: three studies. Arthritis Care Res. 1998;11(6):448-454.

40. Stone RC, Baker J. Painful choices: a qualitative exploration of facilitators and barriers to active lifestyles among adults with osteoarthritis. J Appl Gerontol. Epub 2015 Aug 27.

41. Hunt MA, Birmingham TB, Skarakis-Doyle E, Vandervoort AA. Towards a biopsychosocial framework of osteoarthritis of the knee. Disabil Rehabil. 2008;30(1):54-61.

42. Baert IAC, Meeus M, Mahmoudian A, Luyten FP, Nijs J, Verschueren SMP. Do psychosocial factors predict muscle strength, pain, or physical performance in patients with knee osteoarthritis? J Clin Rheumatol. 2017;23(6):308-316.

43. Volders S, Boddez Y, De Peuter S, Meulders A, Vlaeyen JW. Avoidance behavior in chronic pain research: a cold case revisited. Behav Res Ther. 2015;64:31-37.

44. Paskins Z, Sanders T, Croft PR, Hassell AB. The identity crisis of osteoarthritis in general practice: a qualitative study using video-stimulated recall. Ann Fam Med. 2015;13(6):537-544.

45. Baker R, Camosso-Stefinovic J, Gillies C, et al. Tailored interventions to overcome identified barriers to change: effects on professional practice and health care outcomes. Cochrane Database Syst Rev. 2010;3:CD005470.

46. Hewlett SA. Patients and clinicians have different perspectives on outcomes in arthritis. J Rheumatol. 2003;30(4):877-879.

47. Zhang Y, Jordan JM. Epidemiology of osteoarthritis. Clin Geriatr Med. 2010;26(3):355-369.

48. Van Manen M. Phenomenology of Practice: Meaning-Giving Methods in Phenomenological Research and Writing. Walnut Creek, CA: Left Coast Press; 2014.

49. Croft P, Porcheret M, Peat G. Managing osteoarthritis in primary care: the GP as public health physician and surgical gatekeeper. $B r J$ Gen Pract. 2011;61(589):485-486. 


\section{Supplementary material}

\section{OSTEOARTHRITIS SCREEN}

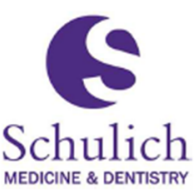

If you have experienced pain in one or more joints (knees, hips, spine, shoulders, fingers/hands, ankles/feet) over the past 12 months, answer the following questions:

1. The pain only started later in life (after 45 years of age).

2. The pain originally started in one joint.

3. The pain appeared gradually over time, not suddenly.

4. The pain in my knee or hip started before the pain in my fingers/hands or feet.

5. Usually the pain is mild or moderate, but it gets worse after using the joint or doing an activity.

6. The joint pain is not as bad when I rest.

7. In the morning, joint stiffness lasts less than 60 minutes.

8. Sometimes the affected joint will lock, preventing full range of motion. (eg.sometimes I can't fully extend my leg)

9. Sometimes I hear a crackling sound in the affected joint.

10. My doctor has previously told me that I have osteoarthritis.

$\begin{array}{lll}\text { YES } & \text { NO } & \text { UNSURE } \\ \text { YES } & \text { NO } & \text { UNSURE } \\ \text { YES } & \text { NO } & \text { UNSURE } \\ \text { YES } & \text { NO } & \text { UNSURE } \\ \text { YES } & \text { NO } & \text { UNSURE } \\ & & \\ \text { YES } & \text { NO } & \text { UNSURE } \\ \text { YES } & \text { NO } & \text { UNSURE } \\ \text { YES } & \text { NO } & \text { UNSURE } \\ & & \\ \text { YES } & \text { NO } & \text { UNSURE } \\ \text { YES } & \text { NO } & \text { UNSURE }\end{array}$

YES NO UNSURE

Figure SI Osteoarthritis Screening test.

Note: Affirmative answers indicate the presence of $O A$.

Abbreviation: OA, osteoarthritis.

The Journal of Pain Research is an international, peer reviewed, open access, online journal that welcomes laboratory and clinical findings in the fields of pain research and the prevention and management of pain. Original research, reviews, symposium reports, hypothesis formation and commentaries are all considered for publication.

\section{Dovepress}

The manuscript management system is completely online and includes a very quick and fair peer-review system, which is all easy to use. Visit http://www.dovepress.com/testimonials.php to read real quotes from published authors. 